\title{
SEBUAH TELAAH ELIPS DAN LINGKARAN MELALUI SEBUAH PENDEKATAN ALJABAR MATRIKS
}

\author{
Rahmat Sagara \\ Sekolah Tinggi Keguruan dan Ilmu Pendidikan Kebangkitan Nasional \\ Sampoerna School of Education Building \\ Jl. Kapten Tendean No. 88 C. 4th Floor, Jakarta Selatan 12710, Indonesia \\ Phone: +62 215772275 Ext. 7243, Fax: +62 215772276 \\ e-mail: rahmat.sagara@sampoernaeducation.ac.id
}

\begin{abstract}
In this article, ellipse and circle will be learnt in depth via matrix algebra approach. The discussion of the both is started from their classic definition continued by surveying ellipse in matrix form. During the survey, some properties about ellipse will be explained and also, the procedure in drawing the figures can be obtained geometrically using some aspect in geometry: rotation and translation. At the end of the discussion, the new definition of the figures is deduced. Both of them are defined as" a set of points in a plane that are the same distance from a fixed point" but in different point of view about the 'distance'. The 'distance' in the definition is derived from different norm definition. The difference lies on the positive definite matrix used in the norm definition. Base on the new definition, we'll have the conclusion that circle is a special type of ellipse.
\end{abstract}

Keywords: circle, distance, ellipse, norm, positive definite matrix

\section{PENDAHULUAN}

Elips dan lingkaran memiliki definisi yang berbeda. Masing-masing didefinisikan sebagai berikut:

\section{Lingkaran didefinisikan sebagai himpunan semua titik-titik pada bidang datar yang berjarak sama terhadap sebuah titik tertentu. Sebuah titik ini disebut titik pusat dari lingkaran. \\ Elips didefinisikan sebagai himpunan semua titik-titik pada bidang datar yang jumlah jaraknya terhadap dua titik-titik tertentu tetap. Kedua titik-titik ini disebut titik-titik fokus dari elips.}

Berdasarkan kedua definisi di atas, sebuah lingkaran bisa disebut elips, yakni elips dengan titik-titik fokusnya berimpit dengan titik pusatnya.

Misalkan $r$ adalah jarak yang dinyatakan pada definisi yang pertama (dengan kata lain $r$ adalah panjang jari-jari dari lingkaran), $\mathrm{t}$ adalah jumlah jarak yang dinyatakan pada definisi kedua, titik-titik fokus dari elips adalah $\mathrm{F}(\mathrm{c}, 0)$ and $\mathrm{F}^{\prime}(-\mathrm{c}, 0)$ dimana $c$ adalah sebuah bilangan real non-negatif, dan tanpa mengurangi keumuman misalkan titik asal $O(0,0)$ adalah titik pusat bagi kedua bangun datar tersebut. Maka bisa ditunjukkan bahwa lingkaran dan elips masing-masing bisa dirumuskan sebagai berikut:

$$
L=\left\{(x, y) \in \mathbb{R}^{2} \mid x^{2}+y^{2}=r^{2}\right\}
$$

dan

$$
E=\left\{(x, y) \in \mathbb{R}^{2} \mid \frac{x^{2}}{t^{2}}+\frac{y^{2}}{t^{2}-4 c^{2}}=\frac{1}{4}\right\} .
$$

Pada bidang Kartesius, jika sembarang titik pada kedua bangun datar itu dinamai dengan $\mathrm{P}$, titik potong dengan sumbu-x dinamai dengan $A$ dan $A^{\prime}$, dan titik potong dengan sumbuy dinamai dengan $B$ dan $B^{\prime}$ maka kedua bangun datar tersebut masing-masing digambarkan seperti Gambar 1 dan Gambar 2.

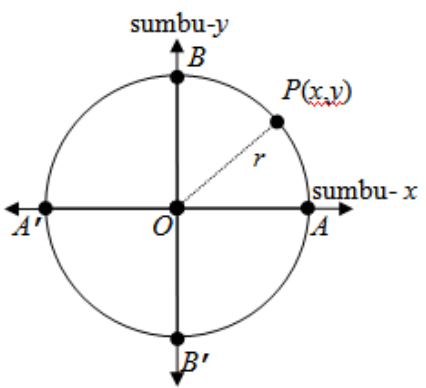

Gambar 1. Lingkaran dengan titik pusat $O(0,0)$ dan panjang jari-jari $r$

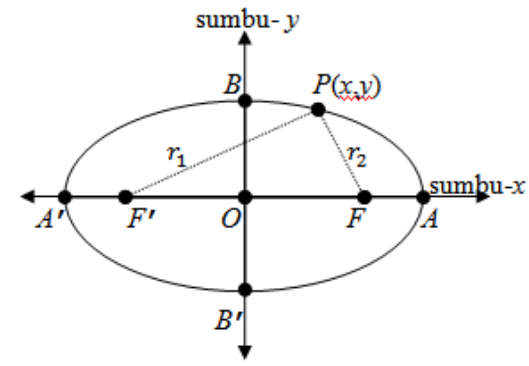

Gambar 2. Elips dengan titik pusat $O(0,0)$ titik-titik fokus $F$ dan $F^{\prime}$ serta jumlah jarak titik pada elips ke titik-titik focus $t=r_{1}+r_{2}$. 
Pandang Gambar 2 dan misalkan bahwa koordinat dari $A, A^{\prime}, B$ dan $B^{\prime}$ berturut-turut adalah $(a, 0),(-a, 0),(b, 0)$, dan $(-b, 0)$, dimana $a$ dan $b$ keduanya adalah bilangan real positif. Jika $P$ berimpit dengan $A$ atau $A^{\prime}$, maka akan didapatkan

$$
t=2 a
$$

dan jika $P$ berimpit dengan $B$ atau $B^{\prime}$, maka akan didapatkan

$$
\frac{1}{4} t^{2}=b^{2}+c^{2} \text {. }
$$

dari Persamaan 1.3 dan 1.4 didapatkan

$$
a^{2}=b^{2}+c^{2} .
$$

Dengan demikian, persamaan elips bisa dituliskan sebagai berikut:

$$
\begin{gathered}
E=\left\{(x, y) \in \mathbb{R}^{2} \mid \frac{x^{2}}{a^{2}}+\frac{y^{2}}{b^{2}}=1\right\} \\
\text { atau } \\
E=\left\{(x, y) \in \mathbb{R}^{2} \mid b^{2} x^{2}+a^{2} y^{2}=a^{2} b^{2}\right\}
\end{gathered}
$$

dimana $a$ dan $b$ keduanya adalah bilangan real positif sebagai mana dipaparkan di atas. bilangan $2 a$ dan $2 b$ masing-masing adalah panjang sumbu mayor dan panjang sumbu minor dari elips.

\section{PEMBAHASAN}

\section{Elips Dalam Pendekatan Aljabar Matriks}

Misalkan $\mathrm{P}(\mathrm{x}, \mathrm{y})$ merupakan sebuah titik pada elips seperti pada Persamaan 1.7. Jelas bahwa $P$ akan memenuhi persamaan

$$
b^{2} x^{2}+a^{2} y^{2}=a^{2} b^{2}
$$

atau dalam bentuk persamaan matriks, $P$ akan memenuhi persamaan:

$$
\left[\begin{array}{ll}
x & y
\end{array}\right]\left[\begin{array}{cc}
b^{2} & 0 \\
0 & a^{2}
\end{array}\right]\left[\begin{array}{l}
x \\
y
\end{array}\right]=a^{2} b^{2} .
$$

Pandang Persamaan 2.2. matriks bujur sangkar yang digunakan pada persamaan itu bersifat definit positif karena simetri dan (sesuai dengan diasumsikan sebelumnya bahwa $a>0$ dan $b>0$ yang mengakibatkan $a^{2}$ dan $b^{2}$ yang tiada lain adalah) nilai-nilai eigen dari matriks itu bernilai positif. Kemudian karena $a^{2}$ dan $b^{2}$ adalah nilai-nilai eigen dari matriks itu, jelas bahwa $a^{2} b^{2}$ adalah nilai determinan dari matriks itu.

Lebih jauh, bahwa secara umum, matriks bujursangkar yang bisa digunakan dalam persamaan elips tidak hanya matriks diagonal, tetapi semua matriks definit positif. Tentunya dua matriks definit positif yang berbeda akan menghasilkan dua buah elips yang berbeda pula.
Dengan demikian, elips bisa dirumuskan sebagai berikut:

$$
E_{1}=\left\{(x, y) \in \mathbb{R}^{2}\left|\left[\begin{array}{ll}
x & y
\end{array}\right] \mathbf{M}\left[\begin{array}{l}
x \\
y
\end{array}\right]=\right| \mathbf{M} \mid\right\}
$$

dimana $\mathbf{M}$ adalah sebuah matriks definit positif berukuran 2x2 dan $|\mathbf{M}|$ adalah determinan dari matriks M. Perumusan ini bisa dijelaskan sebagai berikut:

Karena $\mathbf{M}$ adalah sebuah matriks simetri maka terdapat matriks orthogonal $\mathbf{P}$ dan matriks diagonal $\mathbf{D}$ sedemikian sehingga $\mathbf{M}=\mathbf{P D P} \mathbf{P}^{\mathrm{t}}$, dimana $\mathbf{P}^{t}$ adalah matriks transpos dari P. Semua komponen diagonal dari $\mathbf{D}$ adalah nilai eigen dari M dan karena $\mathbf{M}$ definit positif maka semua komponen diagonal ini positif. Vektor kolom ke- $i$ dari matriks $\mathbf{P}$ adalah vektor eigen satuan dari $\mathbf{M}$ yang bersesuaian dengan nilai eigen ke- $i$ dari $\mathbf{M}$, yakni komponen diagonal ke-i dari D. Dengan demikian, ekspresi:

$$
\left[\begin{array}{ll}
x & y
\end{array}\right] \mathbf{M}\left[\begin{array}{l}
x \\
y
\end{array}\right]
$$

bisa dituliskan sebagai:

dimana

$$
\left[\begin{array}{ll}
u & v
\end{array}\right] \mathbf{D}\left[\begin{array}{l}
u \\
v
\end{array}\right]
$$

$$
\left[\begin{array}{l}
u \\
v
\end{array}\right]=\mathbf{P}^{\mathbf{t}}\left[\begin{array}{l}
x \\
y
\end{array}\right]
$$

dan karena $\mathbf{P}$ merupakan matriks orthogonal, didapatkan juga

$$
\left[\begin{array}{l}
x \\
y
\end{array}\right]=\mathbf{P}\left[\begin{array}{l}
u \\
v
\end{array}\right]
$$

Dengan demikian Persamaan 2.3 bisa dituliskan sebagai:

$$
E_{1}=\left\{(x, y) \in \mathbb{R}^{2} \mid\left[\begin{array}{l}
x \\
y
\end{array}\right]=\mathbf{P}\left[\begin{array}{l}
u \\
v
\end{array}\right] \forall(u, v) \in E_{2}\right\}(2.4)
$$

dimana

$$
E_{2}=\left\{(u, v) \in \mathbb{R}^{2}\left|\left[\begin{array}{ll}
u & v
\end{array}\right] \mathbf{D}\left[\begin{array}{l}
u \\
v
\end{array}\right]=\right| \mathbf{D} \mid\right\}
$$

dan $\mathbf{P}$ dan $\mathbf{D}$ masing masing matriks orthogonal dan matriks diagonal sedemikian sehingga $\mathbf{M}=\mathbf{P D P}^{\mathbf{t}}$ seperti yang telah dipaparkan sebelumnya. Dari Persamaan 2.4 dan 2.5 terlihat bahwa elips yang dirumuskan pada Persamaan 2.3 adalah hasil transformasi $T$ dari elips $E_{2}$, atau $E_{1}=T\left(E_{2}\right)$ dibawah definisi:

$$
T\left(\left[\begin{array}{l}
u \\
v
\end{array}\right]\right)=\mathbf{P}\left[\begin{array}{l}
u \\
v
\end{array}\right]
$$

Lebih dalam, peranan matrks $\mathbf{D}$ dan $\mathbf{P}$ dalam pembentukan elips dipaparkan sebagai berikut:

$$
\text { Pandang matriks } \mathbf{D} \text { dan tulis } \mathbf{D}=\left[\begin{array}{cc}
\lambda_{2} & 0 \\
0 & \lambda_{1}
\end{array}\right] \text {. }
$$

Tanpa mengurangi keumuman asumsikan bahwa $\lambda_{1} \geq \lambda_{2}$, maka elips $E_{2}$ seperti 2.5 adalah elips 
yang berpusat di $O(0,0)$ mempunyai panjang sumbu mayor dan sumbu minor masing-masing adalah $2 \sqrt{\lambda_{1}}$ dan $2 \sqrt{\lambda_{2}}$. Hal ini didapat dari analogi Persamaan 2.5 dan Persamaan 1.6 dimana $\sqrt{\lambda_{1}}$ dan $\sqrt{\lambda_{2}}$ pada Persamaan 2.5 bersesuaian dengan $a$ dan $b$ pada Persamaan 1.6.

Sekarang pandang matriks $\mathbf{P}$ dan tulis

$$
\mathbf{P}=\left[\begin{array}{ll}
p_{11} & p_{12} \\
p_{21} & p_{22}
\end{array}\right]
$$

Karena $\mathbf{P}$ adalah matriks ortognal maka $\mathbf{P P}^{\mathbf{t}}=\mathbf{P}^{\mathbf{t}} \mathbf{P}=\mathbf{I}_{2}$ yaitu matriks identitas orde 2 . Dari persamaan $\mathbf{P P}^{\mathbf{t}}=\mathbf{I}_{\mathbf{2}}$ didapat hubungan:

$$
\left[\begin{array}{cc}
p_{11}^{2}+p_{12}^{2} & p_{11} p_{21}+p_{12} p_{22} \\
p_{21} p_{11}+p_{22} p_{12} & p_{21}^{2}+p_{22}^{2}
\end{array}\right]=\left[\begin{array}{ll}
1 & 0 \\
0 & 1
\end{array}\right]
$$

atau didapat sistem persamaan:

$$
\begin{aligned}
p_{11}^{2}+p_{12}^{2} & =1 \\
p_{11} p_{21}+p_{12} p_{22} & =0 \\
p_{21}^{2}+p_{22}^{2} & =1
\end{aligned}
$$

dan dari persamaan $\mathbf{P}^{\mathbf{t}} \mathbf{P}=\mathbf{I}_{\mathbf{2}}$ ini didapat hubungan:

$$
\left[\begin{array}{cc}
p_{11}^{2}+p_{21}^{2} & p_{11} p_{12}+p_{21} p_{22} \\
p_{12} p_{11}+p_{22} p_{21} & p_{12}^{2}+p_{22}^{2}
\end{array}\right]=\left[\begin{array}{ll}
1 & 0 \\
0 & 1
\end{array}\right]
$$

atau didapat sistem persamaan:

$$
\begin{aligned}
p_{11}^{2}+p_{21}^{2} & =1 \\
p_{11} p_{12}+p_{21} p_{22} & =0 \\
p_{12}^{2}+p_{22}^{2} & =1
\end{aligned}
$$

Dari Persamaan 2.8 dan 2.11 didapatkan

$$
\left(p_{11}-p_{22}\right)\left(p_{12}-p_{21}\right)=0 \text {. }
$$

Pandang Persamaan 2.13 untuk kedua kasus berikut:

1. Kasus $p_{12} \neq p_{21}$

Jika $p_{12} \neq p_{21}$ maka $p_{11}=p_{22} ;$ dan jika $p_{11}=p_{22}$ maka berdasarkan Persamaan 2.7 dan 2.9 (atau Persamaan 2.10 dan 2.12) didapat bahwa $p_{12}^{2}=p_{21}^{2}$ akan tetapi karena $p_{12} \neq p_{21} \quad$ maka $\quad p_{12}=-p_{21}$. Dengan demikian bisa dituliskan bahwa

$$
\mathbf{P}=\left[\begin{array}{cc}
f & -g \\
g & f
\end{array}\right]
$$

dimana $f$ dan $g$ adalah bilagan real yang memenuhi sifat $f^{2}+g^{2}=1$.

2. Kasus $p_{11} \neq p_{22}$

Jika $p_{11} \neq p_{22}$ maka $p_{12}=p_{21}$; dan jika $p_{12}=p_{21}$ maka berdasarkan Persamaan 2.7 dan 2.9 (atau Persamaan 2.10 dan 2.12) didapat bahwa $p_{11}^{2}=p_{22}^{2}$ akan tetapi karena $p_{11} \neq p_{22}$ maka $\quad p_{11}=-p_{22}$. Dengan demikian bisa dituliskan bahwa

$$
\mathbf{P}=\left[\begin{array}{cc}
f & g \\
g & -f
\end{array}\right]
$$

dimana $f$ dan $g$ adalah bilagan real yang memenuhi sifat $f^{2}+g^{2}=1$.

Matriks $\mathbf{P}$ pada Persamaan 2.13 dan 2.14 keduanya memberikan elips yang sama. Hal ini dijamin oleh fakta berikut:

1. Dengan menggunakan matriks $\mathbf{P}$ pada Persamaan 2.13, hasil perkalian dari PDPt:

$$
\begin{aligned}
{\left[\begin{array}{cc}
f & -g \\
g & f
\end{array}\right]\left[\begin{array}{cc}
\lambda_{1} & 0 \\
0 & \lambda_{2}
\end{array}\right]\left[\begin{array}{ll}
f & g \\
-g & f
\end{array}\right] } & \\
& =\left[\begin{array}{ll}
\lambda_{1} f^{2}+\lambda_{2} g^{2} & \left(\lambda_{1}-\lambda_{2}\right) f g \\
\left(\lambda_{1}-\lambda_{2}\right) f g & \lambda_{1} g^{2}+\lambda_{2} f^{2}
\end{array}\right]
\end{aligned}
$$

2. Dengan menggunakan matriks $\mathbf{P}$ pada Persamaan 2.14, hasil perkalian dari PDPt:

$$
\begin{aligned}
{\left[\begin{array}{cc}
f & g \\
g & -f
\end{array}\right]\left[\begin{array}{cc}
\lambda_{1} & 0 \\
0 & \lambda_{2}
\end{array}\right]\left[\begin{array}{cc}
f & g \\
g & -f
\end{array}\right] } \\
=\left[\begin{array}{cc}
\lambda_{1} f^{2}+\lambda_{2} g^{2} & \left(\lambda_{1}-\lambda_{2}\right) f g \\
\left(\lambda_{1}-\lambda_{2}\right) f g & \lambda_{1} g^{2}+\lambda_{2} f^{2}
\end{array}\right]
\end{aligned}
$$

Pada kedua kasus di atas bisa dilihat bahwa keduanya memberikan matriks perkalian PDP $^{\mathrm{t}}$ yang sama. Selain itu, fenomena ini juga bisa dijelaskan dengan fakta bahwa kelipatan dari suatu vektor Eigen yang bersesuaian dengan suatu nilai Eigen tertentu merupakan sebuah vektor Eigen yang bersesuaian dengan nilai Eigen itu. Dengan demikian, apapun bentuk matriks $\mathbf{P}$ yang dipakai, baik pada Persamaan 2.13 maupun pada Persamaan 2.14, tidak akan memberikan elips yang berbeda.

Tranformasi yang didefinisikan pada Persamaan 2.6 jika menggunakan matriks $\mathbf{P}$ seperti pada Persamaan 2.13 secara geometri bisa ditafsirkan sebagai rotasi sebesar $\theta$ (diukur dalam derajat) dengan sumbu rotasi titik asal $O(0,0)$ sedemikian sehingga

$$
f=\cos (\theta) \text { dan } g=\sin (\theta) .
$$

Dengan menulis kembali elips pada Persamaan 2.3 dan ganti $|\mathbf{M}|$ dengan bilangan real positif $k$, maka akan didapatkan elips baru sebagai berikut:

$$
E_{3}=\left\{(x, y) \in \mathbb{R}^{2} \mid\left[\begin{array}{ll}
x & y
\end{array}\right] \mathbf{M}\left[\begin{array}{l}
x \\
y
\end{array}\right]=k\right\}
$$

atau

$$
E_{3}=\left\{(x, y) \in \mathbb{R}^{2} \mid\left[\begin{array}{l}
x \\
y
\end{array}\right]=\mathbf{P}\left[\begin{array}{l}
u \\
v
\end{array}\right] \forall(u, v) \in E_{4}\right\}
$$

dimana

$$
E_{4}=\left\{(u, v) \in \mathbb{R}^{2} \mid\left[\begin{array}{ll}
u & v
\end{array}\right] \mathbf{D}\left[\begin{array}{l}
u \\
v
\end{array}\right]=k\right\}
$$

dan

$$
\mathbf{P}=\left[\begin{array}{cc}
f & -g \\
g & f
\end{array}\right] \text { dan } \mathbf{D}=\left[\begin{array}{cc}
\lambda_{2} & 0 \\
0 & \lambda_{1}
\end{array}\right]
$$

masing-masing adalah matriks orthogonal dan matriks diagonal sehingga $\mathbf{M}=\mathbf{P D P}$. 
Sembarang titik $P^{\prime}(u, v)$ pada elips $E_{4}$ akan memenuhi:

$$
\left[\begin{array}{ll}
u & v
\end{array}\right]\left[\begin{array}{cc}
\lambda_{2} & 0 \\
0 & \lambda_{1}
\end{array}\right]\left[\begin{array}{l}
u \\
v
\end{array}\right]=k
$$

yang ekivalen dengan

$$
\lambda_{2} u^{2}+\lambda_{1} v^{2}=k
$$

atau

$$
\frac{u^{2}}{\frac{k}{\lambda_{2}}}+\frac{v^{2}}{\frac{k}{\lambda_{1}}}=1
$$

Bisa dilihat bahwa Persamaan 2.18 serupa dengan ekspresi yang dipenuhi titik-titik pada elips $E$ seperti pada Persamaan 1.6. Dengan demikian, analogi dengan elips $E$ pada Persamaan 1.6 (dimana $a$ dan $b$ pada persamaan 1.6 masingmasing bersesuaian dengan $\sqrt{\frac{k}{\lambda_{2}}}$ dan $\sqrt{\frac{k}{\lambda_{1}}}$ pada persamaan 2.6), $E_{4}$ adalah elips yang berpusat di $O(0,0)$, panjang sumbu mayor $2 \sqrt{\frac{k}{\lambda_{2}}}$, panjang sumbu minor $2 \sqrt{\frac{k}{\lambda_{1}}}$ dan titik-titik fokus

$$
\left(\sqrt{k \frac{\lambda_{1}-\lambda_{2}}{\lambda_{1} \lambda_{2}}}, 0\right) \text { and }\left(-\sqrt{k \frac{\lambda_{1}-\lambda_{2}}{\lambda_{1} \lambda_{2}}}, 0\right) \text {. }
$$

Hal khusus pada Persamaan 2.18, jika nilai Eigen the Eigen $\lambda_{1}=\lambda_{2}=\lambda$, maka persamaan 2.18 akan menjadi:

$$
u^{2}+v^{2}=\frac{k}{\lambda}
$$

dan persamaan ini serupa dengan ekspresi yang dipenuhi oleh titik-titik pada lingkaran seperti pada Persamaan 1.1. Dengan demikian, pada hal khusus tersebut, elips $E_{4}$ pada Persamaan 2.17 merupakan sebuah lingkaran dengan pusat di $O(0,0)$ dan panjang jari-jari $r=\sqrt{\frac{k}{\lambda}}$, begitu pula dengan Persamaan 2.15 karena matriks orthogonal $\mathbf{P}$ akan berupa matriks identitas yang artinya bahwa lingkaran tersebut dirotasi dengan besar sudut $0^{\circ}$, artinya bahwa transformasi ini tidak merubah bentuk awal.

\section{Elips Dalam Pendekatan Jarak}

Untuk sembarang vektor $\vec{x}=\left[\begin{array}{l}x_{1} \\ x_{2}\end{array}\right] \in \mathbb{R}^{2}$, definisikan sebuah norm dari vektor itu sebagai berikut:

$$
\|\vec{x}\|_{\mathbf{M}}=\sqrt{\vec{x}^{t} \mathbf{M} \vec{x}}
$$

dimana $\mathbf{M}$ adalah sebuah matriks definit positif. Dengan norm ini, definisikan pula jarak antara dua titik $P(x, y)$ dan $Q(u, v)$ sebagai norm dari selisih dua vektor $\left[\begin{array}{l}x \\ y\end{array}\right]$ dan $\left[\begin{array}{l}u \\ v\end{array}\right]$ sebagai berikut:

$$
\begin{aligned}
d_{\mathbf{M}}(P, Q) & =\left\|\left[\begin{array}{l}
x \\
y
\end{array}\right]-\left[\begin{array}{l}
u \\
v
\end{array}\right]\right\|_{\mathbf{M}} \\
& =\left[\begin{array}{ll}
x-u & y-v
\end{array}\right] \mathbf{M}\left[\begin{array}{l}
x-u \\
y-v
\end{array}\right]
\end{aligned}
$$

Dengan demikian jarak $P(x, y)$ dan titik asal $O(0,0)$ adalah

$$
d_{\mathbf{M}}(P, O)=\left\|\left[\begin{array}{l}
x \\
y
\end{array}\right]\right\|_{\mathbf{M}}=\left[\begin{array}{ll}
x & y
\end{array}\right] \mathbf{M}\left[\begin{array}{l}
x \\
y
\end{array}\right]
$$

Berdasarkan definisi jarak pada Persamaan 3.3, bisa dikatakan bahwa elips

$$
E_{3}=\left\{(x, y) \in \mathbb{R}^{2} \mid\left[\begin{array}{ll}
x & y
\end{array}\right] \mathbf{M}\left[\begin{array}{l}
x \\
y
\end{array}\right]=k\right\}
$$

adalah merupakan himpunan semua titik-titik yang berjarak sama terhadap titik asal, yakni sebesar $\sqrt{k}$.

Pusat dari elips bisa diperluas menjadi sembarang titik dengan menggunakan aspek lain dari geometri yaitu translasi. Dengan demikian jika diinginkan bahwa pusat dari elips itu adalah $C(p, q)$, maka translasi dari elips $E_{3}$ harus dilakukan dengan vektor arah translasi $\left[\begin{array}{l}p \\ q\end{array}\right]$ sehingga didapat elips

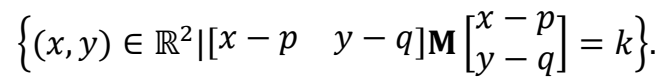

\section{PENUTUP}

Misalkan $C(p, q)$ sebuah titik tertentu dan $P(x, y)$ titik sembarang di dalam bidang kartesius. Misalkan pula $\mathbf{M}$ adalah sebuah matriks definit positif berukuran $2 \times 2$ dan $k$ sebuah bilangan real positif. Pandang definisi jarak pada Persamaan 3.2 dan sebuah himpunan yang diformulasikan sebagai berikut:

$$
\varepsilon=\left\{P \in \mathbb{R}^{2} \mid d_{\mathbf{M}}(P, C)=k\right\}
$$

maka:

1. Jika

$$
\mathbf{P}=\left[\begin{array}{cc}
f & -g \\
g & f
\end{array}\right] \text { dan } \mathbf{D}=\left[\begin{array}{cc}
\lambda_{2} & 0 \\
0 & \lambda_{1}
\end{array}\right]
$$

masing-masing adalah matriks orthogonal dan matriks diagonal sehingga $\mathbf{M}=\mathbf{P D P} \mathbf{P}^{\mathbf{t}}$, maka $\varepsilon$ adalah sebuah elips dengan:

a. titik pusat $C$,

b. merupakan hasil transformasi

$$
T(E)=\left(T_{1} \circ T_{2}\right)(E)
$$

dimana

$$
T_{2}\left(\left[\begin{array}{l}
x \\
y
\end{array}\right]\right)=\left[\begin{array}{cc}
f & -g \\
g & f
\end{array}\right]\left[\begin{array}{l}
x \\
y
\end{array}\right]
$$

adalah rotasi sebesar $\theta$ (diukur dalam derajat) dengan sumbu rotasi titik asal 
$O(0,0)$ sedemikian sehingga $f=\cos (\theta)$ dan $g=\sin (\theta)$,

$$
T\left(\left[\begin{array}{l}
x \\
y
\end{array}\right]\right)=\left[\begin{array}{l}
x+p \\
y+q
\end{array}\right]
$$

adalah translasi dengan arah vektor translasi $\left[\begin{array}{l}p \\ q\end{array}\right]$ dan

$$
E=\left\{\begin{array}{l|l}
(x, y) \in \mathbb{R}^{2} & \frac{x^{2}}{\frac{k}{\lambda_{2}}}+\frac{y^{2}}{\frac{k}{\lambda_{1}}}=1
\end{array}\right\}
$$

adalah elips yang berpusat di $O(0,0)$, panjang sumbu mayor $2 \sqrt{\frac{k}{\lambda_{2}}}$, panjang sumbu minor $2 \sqrt{\frac{k}{\lambda_{1}}}$ dan titik-titik fokus $\left(\sqrt{k \frac{\lambda_{1}-\lambda_{2}}{\lambda_{1} \lambda_{2}}}, 0\right)$ and $\left(-\sqrt{k \frac{\lambda_{1}-\lambda_{2}}{\lambda_{1} \lambda_{2}}}, 0\right)$.

2. Jika

$$
\mathbf{M}=\left[\begin{array}{ll}
\lambda & 0 \\
0 & \lambda
\end{array}\right],
$$

maka $\mathcal{E}$ adalah sebuah lingkaran dengan: a. titik pusat $C$,

b. panjang jari-jari $\sqrt{\frac{k}{\lambda^{\prime}}}$

3. Jika

$$
\mathbf{M}=\left[\begin{array}{ll}
1 & 0 \\
0 & 1
\end{array}\right],
$$

maka $\varepsilon$ adalah sebuah lingkaran dengan:

a. titik pusat $C$,

b. panjang jari-jari $\sqrt{k}$
Akhirnya, dari penelaahan ini bisa dikemukakan definisi dari elips dan lingkaran sebagai berikut:

Elips adalah himpunan semua titik-titik pada bidang datar yang berjarak sama terhadap sebuah titik tertentu,

dimana jarak yang dimaksud didefinisikan seperti pada persamaan 3.2 dan

lingkaran adalah hal khusus dari elips yang mana matriks definit positif yang dipakai dalam definisi jarak itu berupa matriks identitas atau kelipatannya.

\section{DAFTAR PUSTAKA}

[1] Hogg, R. V., and Craig, A. T., (1978), Introduction to statistical Mathematics, $5^{\text {th }}$ ed., Prentice-Hall, Inc.

[2] Mardia, K. V., Kent, J. T., and Bibby, J. M., (1979) Multivariate analysis, Academic Press.

[3] Meyer, C. D., (2000), Matrix Analysis and Applied Linear Algebra, Society for Industrial and Applied Mathematics.

[4] Rich, B., and Thomas, C., (2009), Geometry Scauhm's outlines, $4^{\text {th }}$ ed., McGraw-Hill Companies, Inc.

[5] http://en.wikipedia.org/wiki/Ellipse 